\title{
Sex differences in COVID-19 fatality rate and risk of death: An analysis in 73 countries, 2020-2021
}

\author{
Max Carlos Ramírez-Soto1,2, Gutia Ortega-Cáceres 3 , Hugo Arroyo-Hernández ${ }^{4}$ \\ ${ }^{1}$ School of Public Health and Administration, Universidad Peruana Cayetano Heredia, Lima, Peru; \\ ${ }^{2}$ Facultad de Ciencias de la Salud, Universidad Tecnológica del Perú, Lima, Peru; \\ ${ }^{3}$ Escuela de Posgrado, Universidad Ricardo Palma, Lima, Peru; \\ ${ }^{4}$ Oficina General de Información y Sistemas, Instituto Nacional de Salud, Lima, Peru
}

Article received 26 May, 2021; accepted 4 July, 2021

\section{SUMMARY}

There is a worrying lack of epidemiological data on the sex differential in COVID-19 fatality rates. We examined the Global Health 50/50 tracks of sex-disaggregated infection and mortality COVID-19 data from 73 countries through May 20, 2021. We compared the infection fatality rate (IFR) in men vs. women and risk of death from COVID-19 by country. Of all cases in 73 countries, 42,933,757 were in women and 40,187,894 in men; 1,274,663 men and 971,899 women died. The IFR was higher in males $(3.17 \%)$ than in women $(2.26 \%)$. The IFR in males vs. females varied from country to country, and it was higher in men in Brazil, Yemen,
Mexico, Ecuador, Scotland, Peru, Guatemala, North Macedonia and Afghanistan. Overall, men had a higher odd of death from COVID-19 (OR, 1.22; 95\% CI, 1.13-1.32; $\mathrm{P}=0.00001)$ and in 49 countries, compared to women. Men in Albania and Guatemala had twice the risk of death from COVID-19. Our findings show higher fatality rates among men than among women. These rates vary widely by country, and men have a higher odd of death from COVID-19.

Keywords: COVID-19, SARS-CoV-2, fatality rate, sex.

\section{INTRODUCTION}

lthough SARS-CoV-2 infection does not dis-
criminate by sex, males/females are more
affected and have a higher risk of death from the
coronavirus disease (COVID-19) [1-4]. Moreover,
a systematic review and meta-analysis recently
showed an infection fatality rate (IFR) of $0.68 \%$,
and this rate varied with location (from 0.17 to
$1.7 \%$ ) [5]. Despite this, it is unclear whether wom-
en or men are more likely to die from COVID-19
and what the differences in IFR are in men vs.
women. In this study, we estimated fatality rates

Corresponding author

Max Carlos Ramírez-Soto

E-mail: maxcrs22@gmail.com and risk of death from COVID-19 stratified by sex and geographic distribution.

\section{MATERIALS AND METHODS}

We examined the Global Health 50/50 tracks of infection and death COVID-19. This tracker retrieves the sex-disaggregated data being reported in official governments websites in 173 countries. This tracker provides a comprehensive analysis of national COVID-19 health policies from a gender, equity and human rights lens globally [6]. We include data from 73 of 174 countries tracked by the COVID-19 Sex-Disaggregated Data Tracker through May 20, 2021; i.e., countries that had reported data on both cases and deaths at the same time point [6]. Countries that presentation of partial or incomplete data were excluded of 
study. Countries that had stopped reporting data on cases or deaths by sex were also excluded of study. Global Health 50/50 tracks includes cases and deaths sex-disaggregated data ( $\%$ male and $\%$ female).

We compared the IFR in men vs. women and risk of death from COVID-19 by country. Meta-analyses were performed to estimate odds ratios (ORs) with $95 \%$ confidence interval (CI) associated with male sex and death, based on pooled average effect measures that were weighted according to the size and precision of each report. The Mantel-Haenszel methods was used to calculate the random effects estimates. P-values of $<0.05$ were considered statistically significant. The meta-analytic methods were carried out using RevMan 5, Cochrane, available at: https:/ / revman.cochrane. org/\#/myReviews.

\section{RESULTS}

Of all cases in 73 countries, 42,933,757 were in women and 40,187,894 in men; 1,274,663 men and 971,899 women died. In overall, the IFR was higher in males $(3.17 \%)$ than in women $(2.26 \%)$. The IFR in males vs. females varied from country to country, and it was higher in men in Brazil, Yemen, Mexico, Ecuador, Scotland, Peru, Guatemala, North Macedonia and Afghanistan. The IFR was higher in men and women in Brazil, Yemen, Mexico and Ecuador (Table 1). The IFR was lower in men in Barbados, Bhutan, New Zealand, Norway, Vietnam, Uganda, Maldives and Israel (Table 1). Figure 1 summarizes the number of deaths and total number of confirmed COVID-19 cases for each sex in 72 countries. The forest plot illustrates the estimated OR for the association of death with male sex for each country with $95 \%$ CI. The estimated pooled OR was 1.22 (95\% CI, 1.13-1.32; $p=0.00001$ ). Analysis used a random effects model with individual reports weighted using the indicated weights. Overall, men have a higher odd of death from COVID-19 in 49 countries, compared to women. Men in Albania and Guatemala had twice the risk of death from COVID-19 (Figure 1).

\section{DISCUSSION}

This study findings show that although both sexes show the same susceptibility, males have a higher IFR and risk of death from COVID-19. Our findings in 73 countries (as of May 2021) are

Table 1 - COVID-19 fatality rate in 73 countries, 2020-2021.

\begin{tabular}{|l|c|c|c|c|c|c|}
\hline \multirow{2}{*}{ Country } & \multicolumn{2}{c|}{ COVID-19 cases } & \multicolumn{2}{c|}{ COVID-19 deaths } & \multicolumn{2}{c|}{ COVID-19 fatality rate } \\
\cline { 2 - 7 } & Male, No. & Female, No. & Male, No. & Female, No. & Male, $\%$ & Female, $\%$ \\
\hline Overall & 40187894 & 42933757 & 1274663 & 971899 & 3.17 & 2.26 \\
\hline Afghanistan & 38271 & 19706 & 1551 & 609 & 4.05 & 3.09 \\
\hline Albania & 63375 & 68657 & 1631 & 804 & 2.57 & 1.17 \\
\hline Argentina & 1640609 & 1661744 & 40032 & 28965 & 2.44 & 1.74 \\
\hline Australia & 14633 & 15031 & 441 & 469 & 3.01 & 3.12 \\
\hline Austria & 313269 & 322294 & 5454 & 4806 & 1.74 & 1.49 \\
\hline Bangladesh & 554408 & 226449 & 9379 & 2802 & 1.69 & 1.24 \\
\hline Barbados & 2046 & 1991 & 8 & 5 & 0.39 & 0.25 \\
\hline Belgium & 476628 & 555929 & 12444 & 12280 & 2.61 & 2.21 \\
\hline Belize & 6664 & 6078 & 211 & 112 & 3.17 & 1.84 \\
\hline Bermuda & 1115 & 1362 & 17 & 15 & 1.52 & 1.10 \\
\hline Bhutan & 854 & 442 & 1 & 0 & 0.12 & 0.00 \\
\hline Bosnia and Herzegovina & 49260 & 46354 & 1858 & 1067 & 3.77 & 2.30 \\
\hline Brazil & 317396 & 248069 & 126614 & 95205 & 39.89 & 38.38 \\
\hline Cambodia & 6533 & 8818 & 60 & 46 & 0.92 & 0.52 \\
\hline Canada & 644355 & 655534 & 12268 & 12451 & 1.90 & 1.90 \\
\hline
\end{tabular}


Continue >>>

\begin{tabular}{|c|c|c|c|c|c|c|}
\hline \multirow{2}{*}{ Country } & \multicolumn{2}{|c|}{ COVID-19 cases } & \multicolumn{2}{|c|}{ COVID-19 deaths } & \multicolumn{2}{|c|}{ COVID-19 fatality rate } \\
\hline & Male, No. & Female, No. & Male, No. & Female, No. & Male, \% & Female, \% \\
\hline Chad & 2520 & 942 & 90 & 24 & 3.57 & 2.55 \\
\hline Colombia & 1504956 & 1626454 & 50951 & 30858 & 3.39 & 1.90 \\
\hline Costa Rica & 144659 & 143967 & 2248 & 1377 & 1.55 & 0.96 \\
\hline Czech Republic & 794766 & 838875 & 17121 & 12623 & 2.15 & 1.50 \\
\hline Denmark & 134034 & 136523 & 1358 & 1145 & 1.01 & 0.84 \\
\hline Ecuador & 210867 & 199062 & 12852 & 6847 & 6.09 & 3.44 \\
\hline England & 1791359 & 2062684 & 70986 & 59407 & 3.96 & 2.88 \\
\hline Equatorial Guinea & 4463 & 3231 & 71 & 32 & 1.59 & 0.99 \\
\hline Estonia & 59822 & 68262 & 641 & 582 & 1.07 & 0.85 \\
\hline Eswatini & 8901 & 9516 & 346 & 325 & 3.89 & 3.42 \\
\hline Finland & 47751 & 42498 & 518 & 462 & 1.08 & 1.09 \\
\hline France & 2657033 & 3011908 & 46503 & 33911 & 1.75 & 1.13 \\
\hline Germany & 1732974 & 1844594 & 45049 & 41120 & 2.60 & 2.23 \\
\hline Greece & 190750 & 182757 & 6638 & 4833 & 3.48 & 2.64 \\
\hline Guatemala & 128432 & 111002 & 5507 & 2386 & 4.29 & 2.15 \\
\hline Guinea-Bissau & 2260 & 1486 & 46 & 21 & 2.04 & 1.41 \\
\hline Haiti & 7574 & 6024 & 164 & 112 & 2.17 & 1.86 \\
\hline Hong Kong & 5663 & 6163 & 123 & 87 & 2.17 & 1.41 \\
\hline Indonesia & 853136 & 895094 & 27341 & 21136 & 3.20 & 2.36 \\
\hline Iraq & 656153 & 486772 & 8908 & 7087 & 1.36 & 1.46 \\
\hline Israel & 410867 & 417829 & 3623 & 2755 & 0.88 & 0.66 \\
\hline Italy & 2004903 & 2100139 & 68715 & 53056 & 3.43 & 2.53 \\
\hline Jamaica & 20883 & 26503 & 497 & 392 & 2.38 & 1.48 \\
\hline Jersey & 1487 & 1750 & 43 & 26 & 2.88 & 1.50 \\
\hline Jordan & 343844 & 330359 & 5712 & 3564 & 1.66 & 1.08 \\
\hline Kenya & 100749 & 65257 & 2065 & 956 & 2.05 & 1.47 \\
\hline Latvia & 56338 & 72346 & 1148 & 1132 & 2.04 & 1.56 \\
\hline Liberia & 1415 & 727 & 56 & 29 & 3.96 & 3.99 \\
\hline Luxembourg & 34620 & 34620 & 436 & 372 & 1.26 & 1.07 \\
\hline Maldives & 26570 & 17073 & 61 & 34 & 0.23 & 0.20 \\
\hline Mexico & 1191251 & 1190298 & 137670 & 82814 & 11.56 & 6.96 \\
\hline Moldova & 105188 & 148766 & 2960 & 3074 & 2.81 & 2.07 \\
\hline Netherlands & 748885 & 822422 & 9493 & 7890 & 1.27 & 0.96 \\
\hline New Zealand & 1307 & 1352 & 14 & 12 & 1.07 & 0.89 \\
\hline Nigeria & 93416 & 62226 & 1104 & 453 & 1.18 & 0.73 \\
\hline North Macedonia & 78494 & 76204 & 3267 & 1944 & 4.16 & 2.55 \\
\hline Northern Ireland & 56955 & 64899 & 1136 & 1015 & 1.99 & 1.56 \\
\hline Norway & 63945 & 55825 & 421 & 360 & 0.66 & 0.64 \\
\hline Peru & 968116 & 916479 & 43442 & 22469 & 4.49 & 2.45 \\
\hline
\end{tabular}


Continue $\gg>$

\begin{tabular}{|c|c|c|c|c|c|c|}
\hline \multirow{2}{*}{ Country } & \multicolumn{2}{|c|}{ COVID-19 cases } & \multicolumn{2}{|c|}{ COVID-19 deaths } & \multicolumn{2}{|c|}{ COVID-19 fatality rate } \\
\hline & Male, No. & Female, No. & Male, No. & Female, No. & Male, \% & Female, \% \\
\hline Philippines & 610774 & 554497 & 11600 & 8041 & 1.90 & 1.45 \\
\hline Portugal & 382534 & 459496 & 8935 & 8074 & 2.34 & 1.76 \\
\hline Republic of Ireland & 120945 & 131761 & 2589 & 2332 & 2.14 & 1.77 \\
\hline Romania & 495506 & 576785 & 17080 & 12491 & 3.45 & 2.17 \\
\hline Rwanda & 15378 & 10837 & 223 & 122 & 1.45 & 1.13 \\
\hline Scotland & 104941 & 124488 & 5142 & 4967 & 4.90 & 3.99 \\
\hline Slovakia & 184174 & 201612 & 6230 & 5368 & 3.38 & 2.66 \\
\hline Slovenia & 118180 & 132255 & 2269 & 2383 & 1.92 & 1.80 \\
\hline South Africa & 679805 & 927678 & 26586 & 29069 & 3.91 & 3.13 \\
\hline South Korea & 66629 & 66842 & 952 & 960 & 1.43 & 1.44 \\
\hline Spain & 1723340 & 1889533 & 43822 & 35466 & 2.54 & 1.88 \\
\hline Sweden & 513205 & 533938 & 7784 & 6517 & 1.52 & 1.22 \\
\hline Switzerland & 328987 & 356974 & 5521 & 4695 & 1.68 & 1.32 \\
\hline USA & 12470540 & 13618456 & 314864 & 259181 & 2.52 & 1.90 \\
\hline Uganda & 30114 & 11308 & 98 & 228 & 0.33 & 2.02 \\
\hline Ukraine & 864038 & 1296057 & 25689 & 22780 & 2.97 & 1.76 \\
\hline Vietnam & 1671 & 1661 & 13 & 22 & 0.78 & 1.32 \\
\hline Wales & 96175 & 115852 & 3092 & 2469 & 3.21 & 2.13 \\
\hline Yemen & 4235 & 2382 & 879 & 377 & 20.75 & 15.83 \\
\hline
\end{tabular}

different from those of another study that reported the IFR in 38 countries or regions (as of May 2020) sex-disaggregated [10]. In our study the IFR was higher in men and women in Brazil, Yemen, Mexico, Ecuador, Scotland, Peru, Guatemala, North Macedonia and Afghanistan, whereas the previous study of Scully et al. the IFR was higher in England, Netherlands, Italy, Sweden, and Belgium [10]. These differences can be explained by the small number of cases and deaths of COVID-19 included in the initial period of the pandemic (as of May 2020), while our study included totals of $40,187,894$ cases in men and $42,933,757$ cases in women, and 1,274,663 deaths in men and 971,899 deaths in women. Subsequently, with more data emerging until May 2021, the trend in fatality rate for COVID-19 has been increased.

The differences in IFR and risk of COVID-19 death in males vs. females could be associated with comorbidities such as hypertension and cardiovascular disease, lung disease and cancer although some countries may have a higher burden of these chronic diseases, their prevalence is high- er in men than women [7-9]. Other factor apart from sex that affect the IFR of COVID-19 and risk of death is age; in this context, previous studies reveal the mortality and fatality rates increased with age and are predominant in men 50 years of age or older [10]. Regardless of the demographics, comorbidities or health systems in each country, there is a consistent biological phenomenon that explains the higher mortality rates in men (immunological mechanisms, genetic factor, inflammation, cancer, etc.) $[1,3,8]$.

Experimental and epidemiological evidence suggests that most biomarkers for infection risk and severity of COVID-19 differ by sex. Although women generally have a more robust immune response sustained with age, men are more likely to develop cytokine storm or immunopathological damage associated with adverse clinical outcomes. Further research on sex hormone immunomodulation, age, and X-linked gene expression may help explain poorer survival in men. Although this relationship is complex, and the available data is not uniformly consistent $[10,11]$. 
Figure 1 - Male sex is associated with a significantly increased risk of mortality from COVID-19.

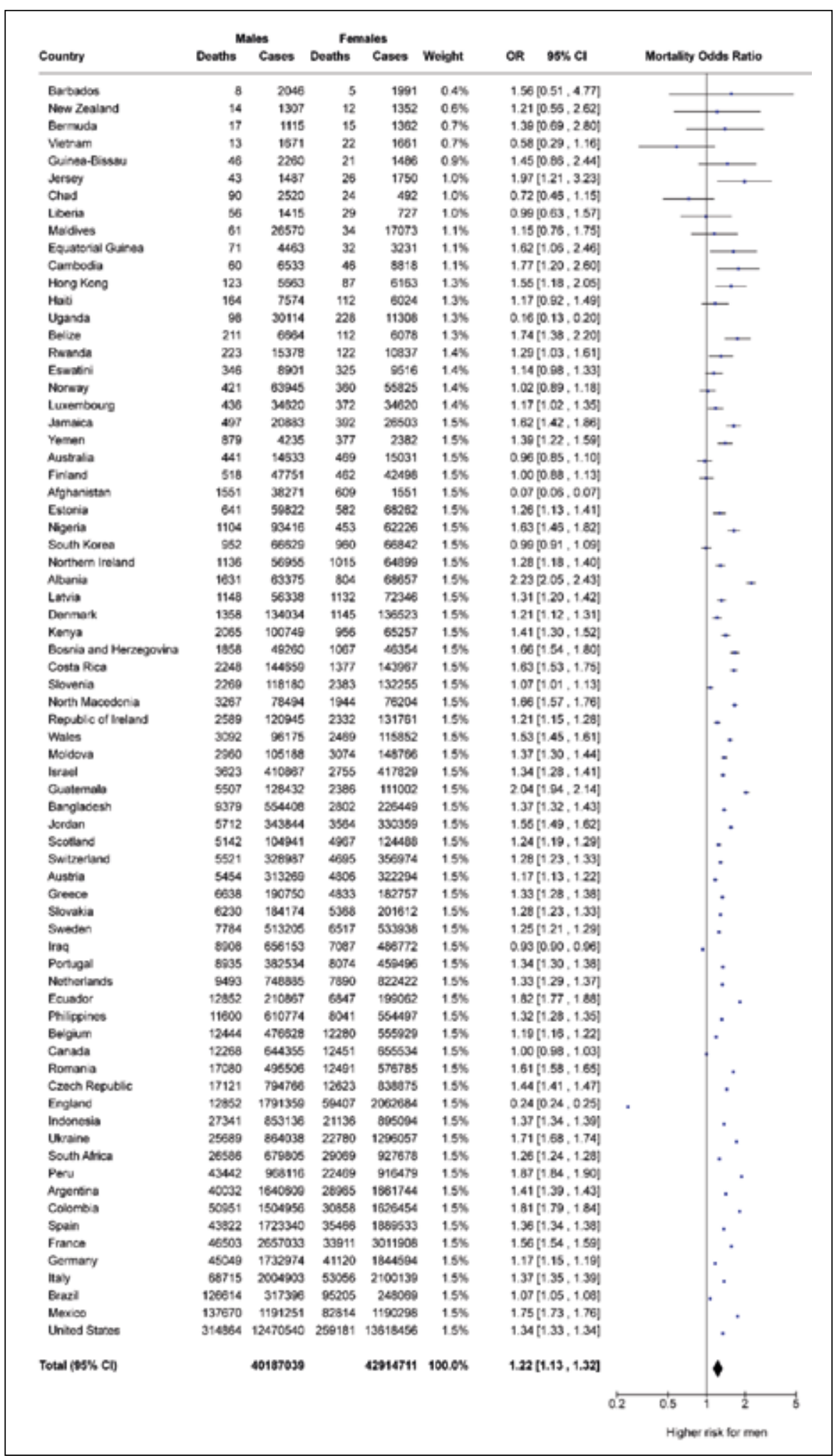


The IFRs and risk of COVID-19 associated death in males vs. females vary widely by country. The IFR and risk of death could be to health system variations from each country, i.e., infrastructure, overload of the health system, intensive care unit beds, medical staff, medicines, etc. [7] . However, these conditions could vary from country to country, leading to a range of hypotheses. Our findings show that in some countries, the IFR is lower in men or similar to women, which could be due to better living conditions and medical care in the long-lived population of developed countries, compared to underdeveloped countries. These differences can also be explained by control measures or vaccination coverages against COVID-19 implemented in countries as New Zealand or Israel [12, 13].

This report has several limitations. First, detailed information was unavailable in 98 countries; therefore, these findings only provide an approximate estimate of IFR and risk of death from SARS$\mathrm{CoV}-2$. Second, the data on cases and deaths are not up to date in all countries; consequently, the true IFR may be higher, thus resulting in possible bias. Third, in some countries, asymptomatic cases of COVID-19 and individuals who are misdiagnosed could be left out of the denominator, leading to its underestimation and overestimation of the IFR in 73 countries. Despite these limitations, these findings provide evidence for public health authorities with the aim of mortality prevention for COVID-19. Furthermore, sex-disaggregated data could be of use to ensure better targeting of gender-equitable prevention efforts.

In summary, our findings show higher fatality rates among men than among women. These rates vary widely by country, and men have a higher odd of death from COVID-19. In countries where men having higher fatality rate, public interventions could personalize health messages and implement prevention and surveillance strategies targeting men with recognized risk factors.

\section{Conflicts of interest}

The authors declare no conflict of interest.

\section{Authors contributions}

MCRS designed the study. MCRS and GOC collected all data. MCRS and HAH performed the statistical analysis. All authors were involved in the interpretation of data. MCRS, GOC and $\mathrm{HAH}$ drafted the manuscript. All authors were involved in the critical revision and approved the final manuscript.

\section{Funding}

This research received no external funding.

\section{REFERENCES}

[1] Williamson EJ, Walker AJ, Bhaskaran K, et al. Factors associated with COVID-19-related death using OpenSAFELY. Nature. 2020; 584 (7821), 430-36.

[2] Bhopal SS, Bhopal R. Sex differential in COVID-19 mortality varies markedly by age. Lancet. 2020; 396 (10250), 532-33.

[3] Gebhard C, Regitz-Zagrosek V, Neuhauser, HK, Morgan R, Klein SL. Impact of sex and gender on COVID-19 outcomes in Europe. Biol Sex Differ. 2020; 11 (1), 29. [4] Jin JM, Bai P, He W, et al. Gender differences in patients with COVID-19: Focus on severity and mortality. Front Public Health. 2020; 8, 152.

[5] Meyerowitz-Katz G, Merone L. A systematic review and meta-analysis of published research data on COVID-19 infection fatality rates. Int J Infect Dis. 2020; 101, 138-48.

[6] Global Health 50/50. The COVID-19 sex-disaggregated data tracker. Date accessed: May 17, 2021. Available in: https://globalhealth5050.org/the-sex-genderand-covid-19-project/

[7] Peckham H, de Gruijter NM, Raine C, et al. Male sex identified by global COVID-19 meta-analysis as a risk factor for death and ITU admission. Nat Commun. 2020; $11(9), 6317$.

[8] Bienvenu LA, Noonan J, Wang X, Peter K. Higher mortality of COVID-19 in males: sex differences in immune response and cardiovascular comorbidities. Cardiovasc Res. 2020; 116 (14), 2197-206.

[9] GBD 2017 Disease and Injury Incidence and Prevalence Collaborators. Global, regional, and national incidence, prevalence, and years lived with disability for 354 diseases and injuries for 195 countries and territories, 1990-2017: a systematic analysis for the global burden of disease study 2017. Lancet. 2018; 392,1789-858. [10] Scully EP, Haverfield J, Ursin RL, Tannenbaum C, Klein SL. Considering how biological sex impacts immune responses and COVID-19 outcomes. Nat Rev Immunol. 2020; 20 (7), 442-7.

[11] Long-Quan L, Tian H, Yong-Qing W, et al. COVID-19 patients' clinical characteristics, discharge rate, and fatality rate of meta-analysis. J Med Virol. 2020; 92 (6), 577-83.

[12] Baker MG, Wilson N, Anglemyer A. Successful Elimination of Covid-19 Transmission in New Zealand. N Engl J Med. 2020; 383 (8), e56

[13] Our World in Data. Coronavirus (COVID-19) Vaccinations. Available in: https://ourworldindata.org/ covid-vaccinations. 